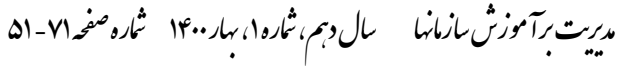

\section{فراتحليل عوامل همبسته با تعهد عاطفى معلمان جمهورى اسلامى ايران}

رامين غريبز اده، دانشجوى دكترى مديريت آموزشى، كروه علوم تربيتى، دانشكده روانشناسى و علوم تربيتى، دانشخاه محقق اردبيلى، اردبيل، ايران.

عادل زاهد بابلان، استاد مديريت آموزشى، گروه علوم تربيتى،دانشكده روانشناسى و علوم تربيتى، دانشكاه محقق ارتق اردبيلى، اردبيل، ايران.

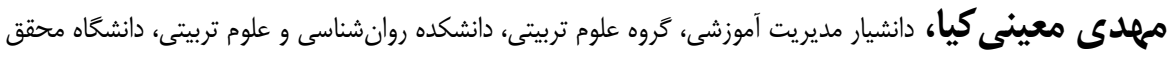
اردبيلى، اردبيل، ايران.

"سليى بلوج)، دانشجوى دكترى مديريت آموزشى، كروه علوم تربيتى، دانشكده ادبيات و علوم انسانى، دانشخاه اروميه، اروميه، ايران.

קكيده

اين يزوهش به منظور توصيف، تحليل و تركيب ارائه شده در زمينه عوامل همبسته با تعهد عاطفى است. روش اين

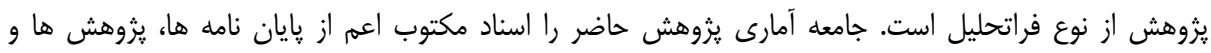

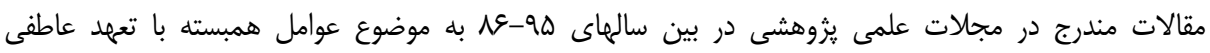

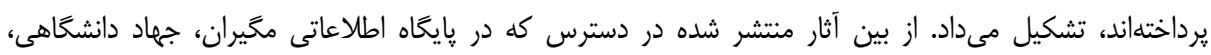

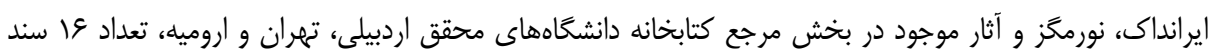

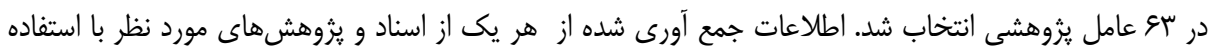

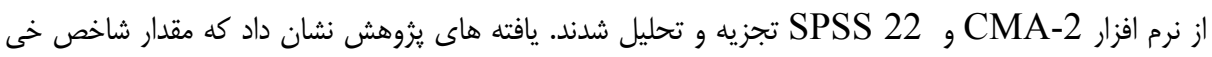

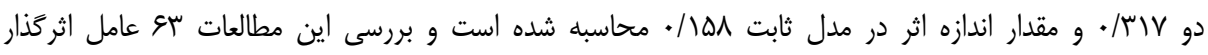

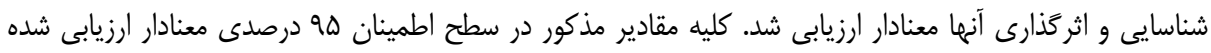
است.

وازَّان كليدى: تعهد سازمانى، تعهد عاطفى، معلمان، فراتحليل.

* نويسنده مسئول: s.balouch@urmia.ac.ir * دريافت مقاله: 99/N/Tr يذيرش مقاله: 99/1/ 


\title{
Meta-analysis of the factors correlated with the emotional commitment of the teachers of the Islamic Republic of Iran
}

Ramin Gharibzadeh, PhD Student in Educational Management, Department of Educational Sciences, Faculty of Psychology and Educational Sciences, Mohaghegh Ardabili University, Ardabil, Iran.

Adel Zahed Bablan, Professor of Educational Management, Department of Educational Sciences, Faculty of Psychology and Educational Sciences, Mohaghegh Ardabili University, Ardabil, Iran.

Mehdi Moeinikia, Associate Professor of Educational Management, Department of Educational Sciences, Faculty of Psychology and Educational Sciences, Mohaghegh Ardabili University, Ardabil, Iran.

*Salim Balouch, PhD Student in Educational Management, Department of Educational Sciences, Faculty of Literature and Humanities, Urmia University, Urmia, Iran.

\begin{abstract}
This study aims to describe, analyze and combine the factors associated with emotional commitment. The method of this research is meta-analysis. The statistical population of the present study consisted of written documents including dissertations, researches and articles in scientific research journals between the years 2007-2017 on the subject of factors associated with emotional commitment. Among the available published works in the database of Migiran, SID, Irandak, Noormagz and the works in the reference section of the library of Mohaghegh Ardabili, Tehran and Urmia universities, 16 documents were selected in 63 research factors. Data collected from each of the documents and research were analyzed using CMA-2 and SPSS 22 software. Findings showed that the value of chi-square index was 0.317 and the value of effect size in the fixed model was 0.158 and the review of these studies identified 63 effective factors and their effectiveness was significant. All the mentioned values have been evaluated as significant at the $95 \%$ confidence level.
\end{abstract}

Keywords: Organizational Commitment, Emotional commitment, Teachers, Meta-analysis.

* Corresponding author: s.balouch@urmia.ac.ir

Receiving Date: 12/11/2020 Acceptance Date: 26/2/2021 
امروزه در سازمانها به منابع انسانى به عنوان مهمترين منابع سازمان نخريسته مىشود و مديران

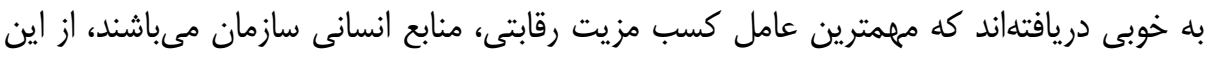

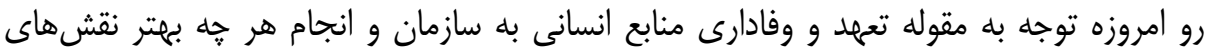

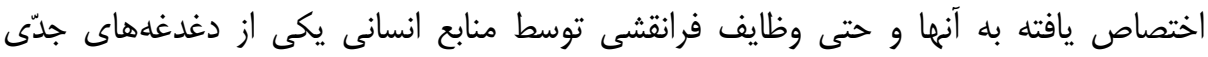
مديران سازمان ها مىباشد.

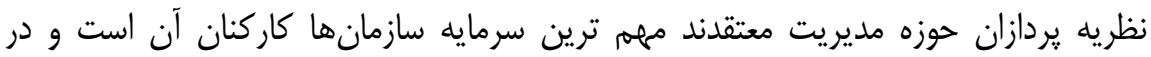

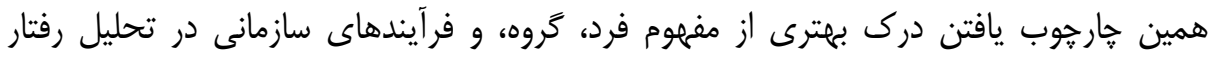

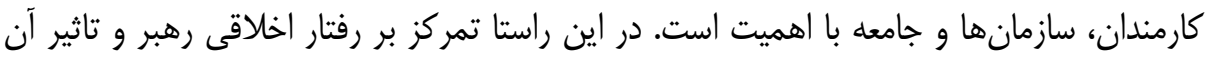

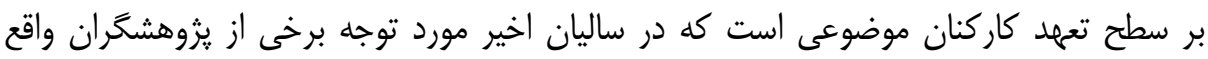

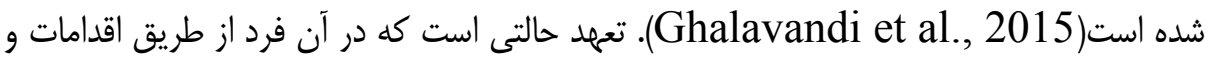

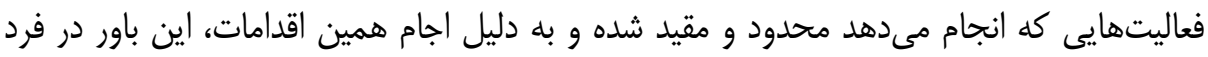

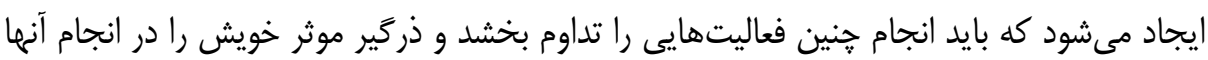

حفظ نمايد (Motahari Nejad and Gemini, 2020).

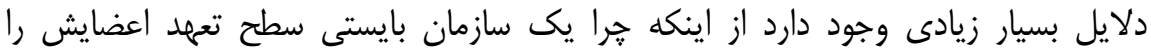

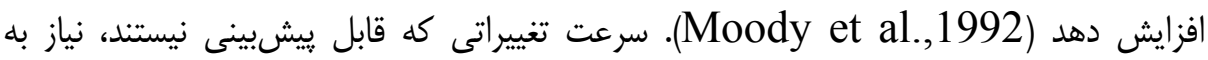
كاركنان متعهد، بر انخيخته را ييش از ييش ضرورى كرده است(إ) (Ardalan et al., 2019).

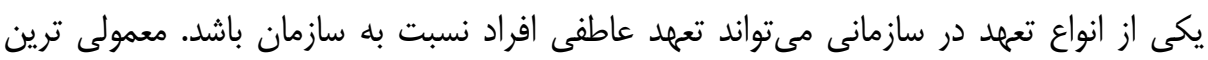

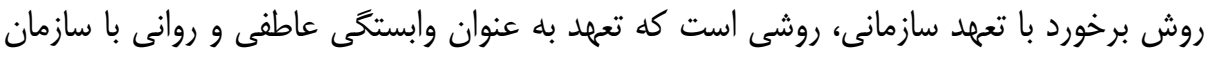

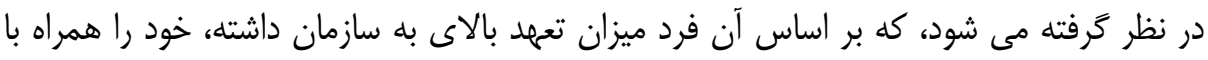

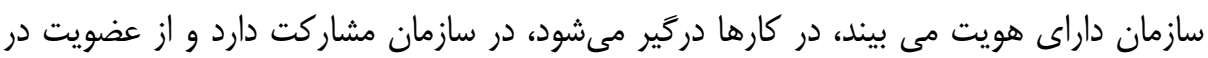

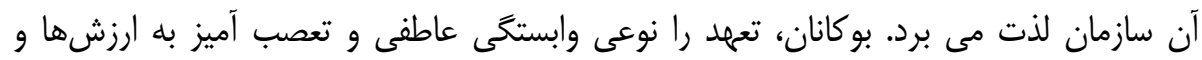

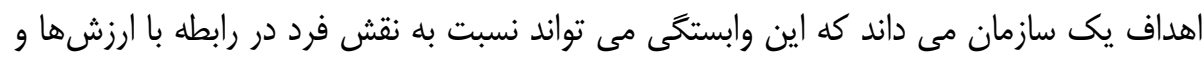

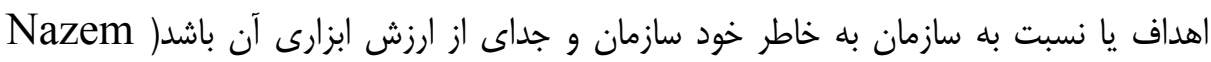
.and Qaed Mohammadi,2008

از منظرى، تعهد عاطفى عبارت است از دلبستخى و علاقه ى قوى به سازمان و تعيين هويت

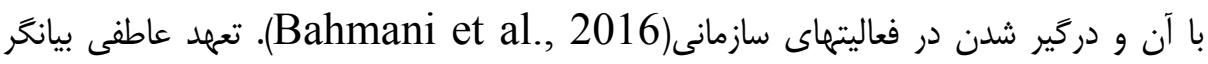




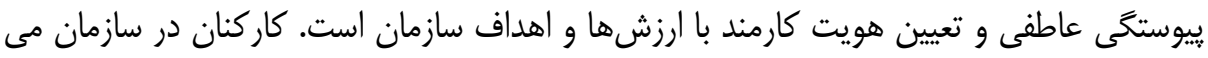

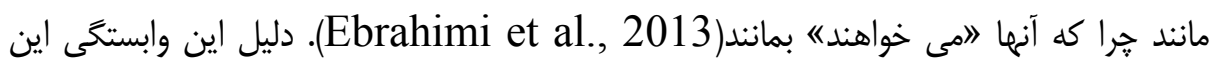

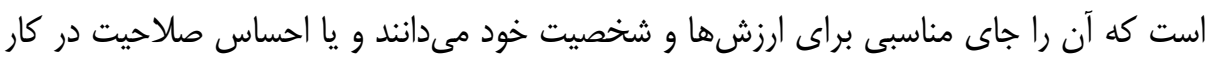

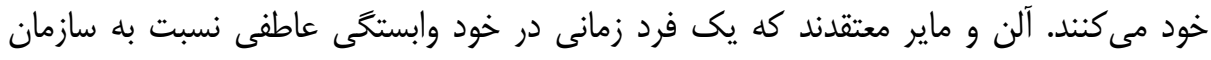

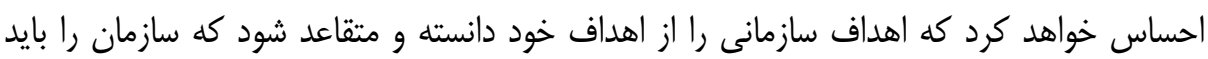

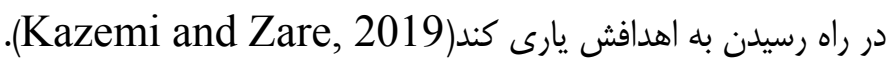

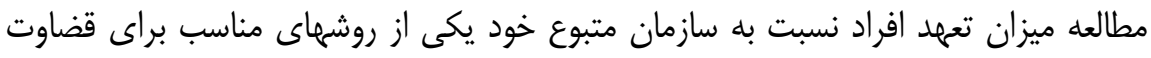

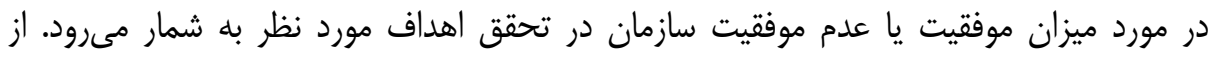

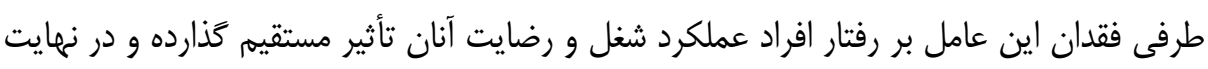

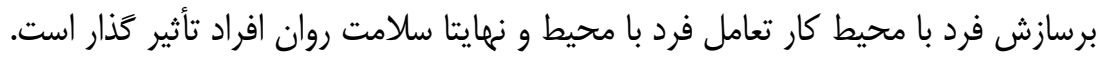

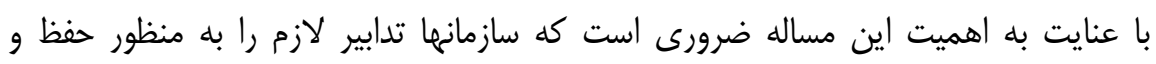

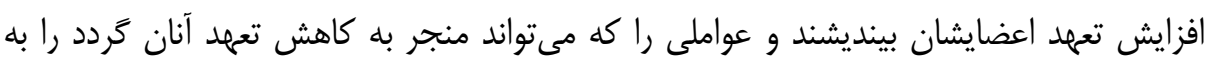
حداقل ممكن رسانده و از ميان بردارند.

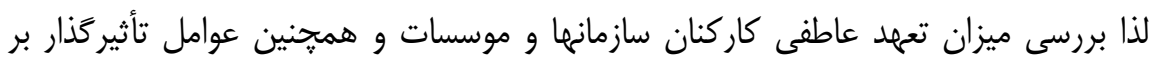

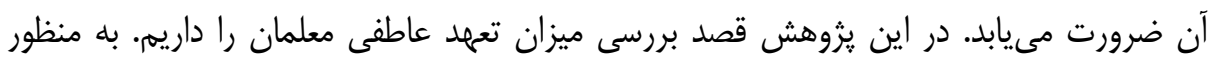

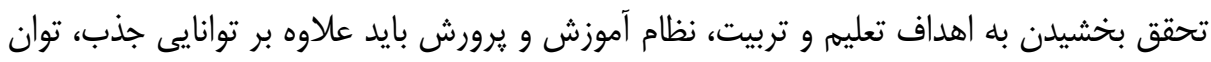

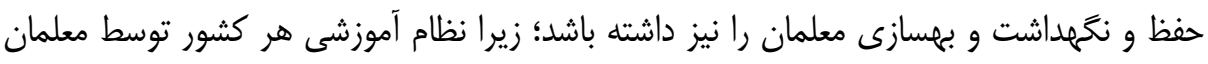

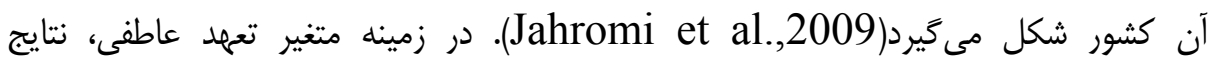

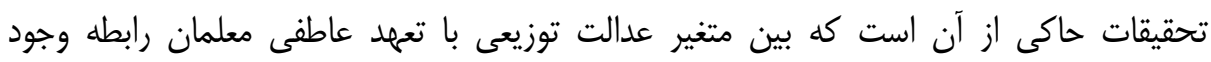

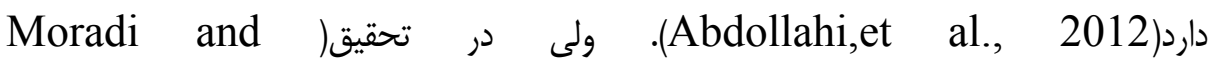
(Talepasand,2015 عدم رابطه بين عدالت توزيعى و تعهد سازمانى كزارش شده است است.

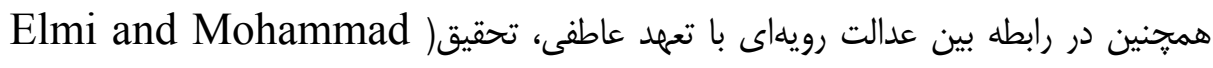

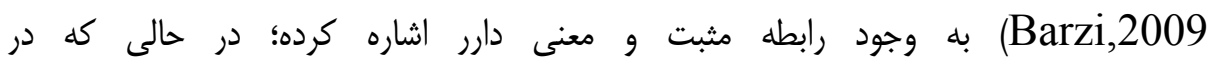
تحقيق(Abdollahi,et al.,2012)به عدم وجود رابطه بين اين دو متغير تاكيد شده است.

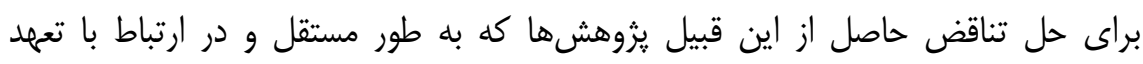

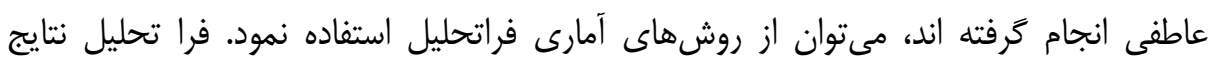


مطالعات مختلف را به مقياس مشترى تبديل مى كند و با روشهاى آمارى رابطه بين ويثگىهاى مطالعات و يافتهها را مورد بررسى قرار مىدهد. اين نتايج متناقض در بعضى تحقيقات ديخر در زمينه ارتباط ساير متغيرها با تعهلد عاطفى نيز

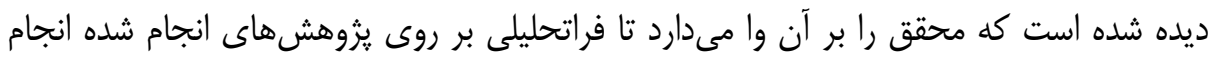
دهد و نتايج دقيق و يكسانى را عرضه كند.

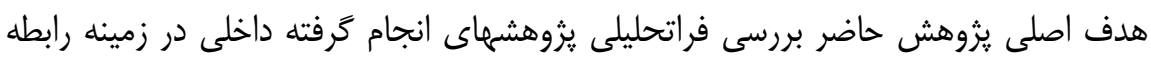

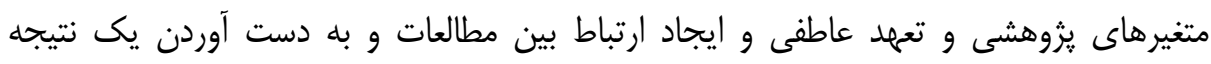

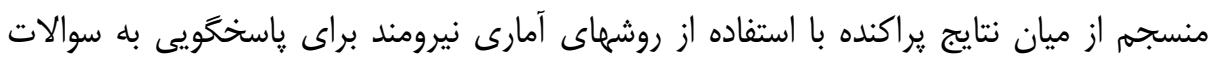
تحقيق است.

\section{روش شناسى ثيزوهش}

با توجه به اينكه هدف اين يزوهش؛ توصيف، تحليل ونيل و تركيب مطالعات ارائه شده در زمينه عوامل

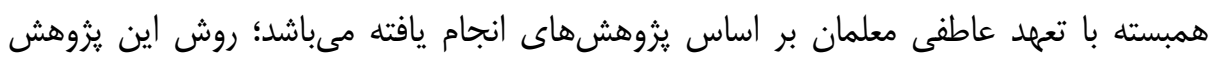

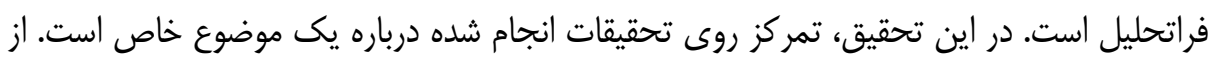

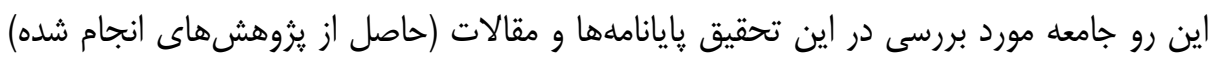

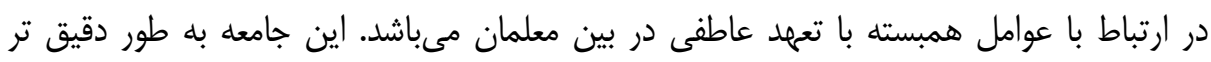

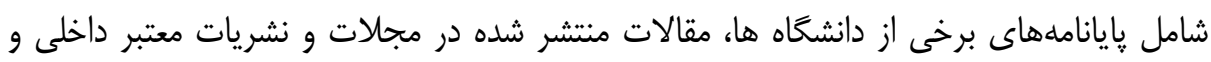

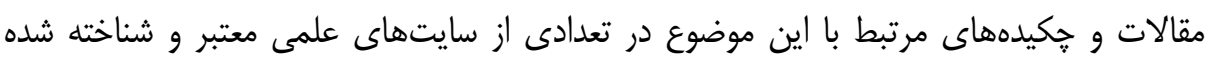

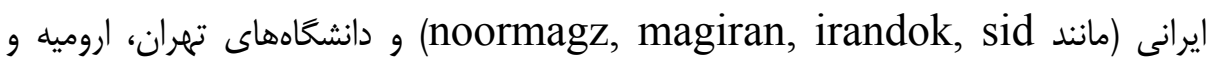
اردبيل كه سوع عامل و فرضيه در قالب عا تحقيق شناسايى گرديد؛ مىباشد.

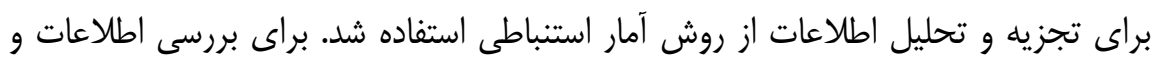
ياسخ گويى به سوالات يزوهش در بخش استنباطى از نرم افزار

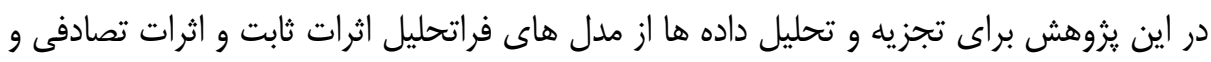

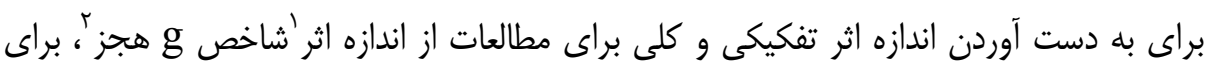

1. Effect Size

2. Hedges 
بررسى سوكيرى انتشار از نمودارهاى قيفى' (فونل هالات) 'و و آزمون اصلاح و برازش دوروال

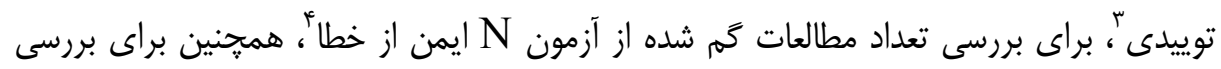

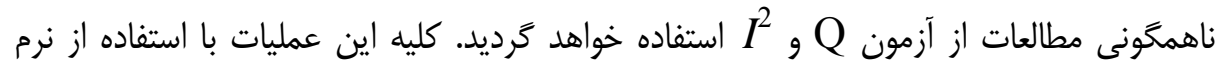

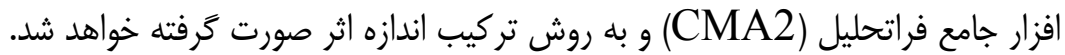

جدول (1): نمونه آمارى مورد مطالعه

\begin{tabular}{|c|c|c|c|c|c|c|c|}
\hline حجم نمونه & سال & نام و نام خانوادگى & رديف & حجم نمونه & سال & نام و نام خانوادگى & رديف \\
\hline מזr & ( & فيروز راد & 9 & r19. & (IM & صلاح الدين محمدى & 1 \\
\hline Fへ૬ & (1\%9 & بيثن عبدالهى & 1. & 11. & Irk. & علمى & $r$ \\
\hline r ז & (1) & صفورا شورونى & 11 & 111 & IrM & امين شايان جهرمى & r \\
\hline ITK & 1ra & اسماعيل قدرى & ir & IV. & 11119 & شريفى & f \\
\hline שr. & $1 \% 99$ & عابدى & $\pi$ & سזו & $1 \% q$. & هويدا & $\Delta$ \\
\hline $11 \pi$ & 11494 & قلاوندى & If & 194 & 1149. & رضان نزاد & 8 \\
\hline $1 \cdots$ & $1 \% 90$ & طهماسب زاده & 10 & $r \Delta \Lambda$ & $\mid r q 1$ & نادى & v \\
\hline$r .$. & 1190 & سعيد مرادى & 19 & $v^{m}$ & 1rar & ابراهيمى & $\Lambda$ \\
\hline
\end{tabular}

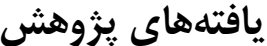

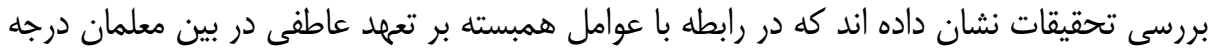

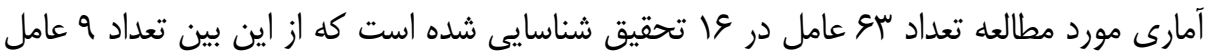

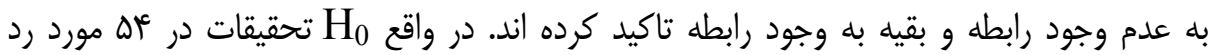

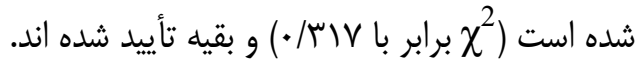

جدول (Y): آمار توصيفى و محاسبه خى دو فرضيههاى تحقيقات

\begin{tabular}{|c|c|c|c|c|}
\hline & $\mathrm{F}_{\mathrm{o}}$ & $\mathrm{F}_{\mathrm{e}}$ & $\mathrm{F}_{0}-\mathrm{F}_{\mathrm{e}}$ & $\chi^{2}$ \\
\hline 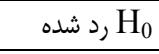 & $\Delta F$ & & & . \\
\hline H & 9 & $\Delta / 9 \mathrm{~V}$ & $r / \mu$ & $.1 .0 \mathrm{r}$ \\
\hline كل ("'s عامل) & \multicolumn{4}{|c|}{ "َو عامل وارد تحليل شده اند. } \\
\hline
\end{tabular}

1. Eggers regression intercept

2. Funnel Plot

3. Duval Tweed fitting

4. classic fail -safe $\mathrm{N}$ 


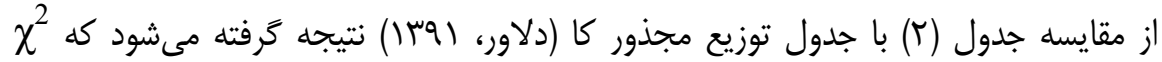

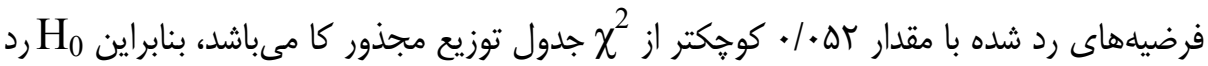
مىشود و H

$$
\chi_{q}^{2}=. / \Delta r<\chi_{C}^{2}=|\Delta / \Delta|
$$

در بخش بعدى ابتدا نمودار قيفى براساس شاخصهاى خطاى استاندارد و دقت در هر يكى از

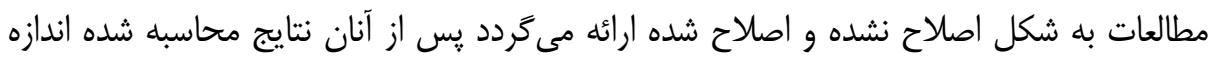

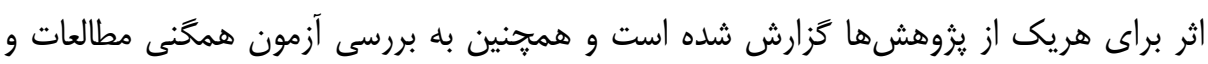

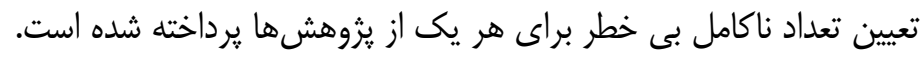

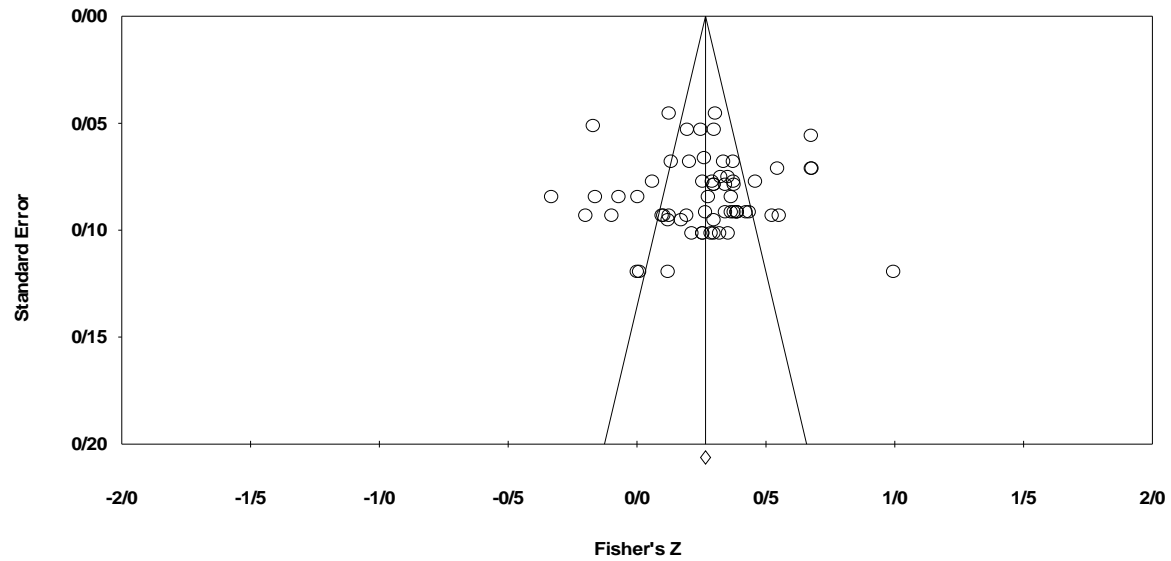

نمودار ( (): نمودار قيفى بر اساس شاخص خطاى استاندارد در يزوهش هاى اوليه 


\section{هديريت بر آهوزش سازمانها}

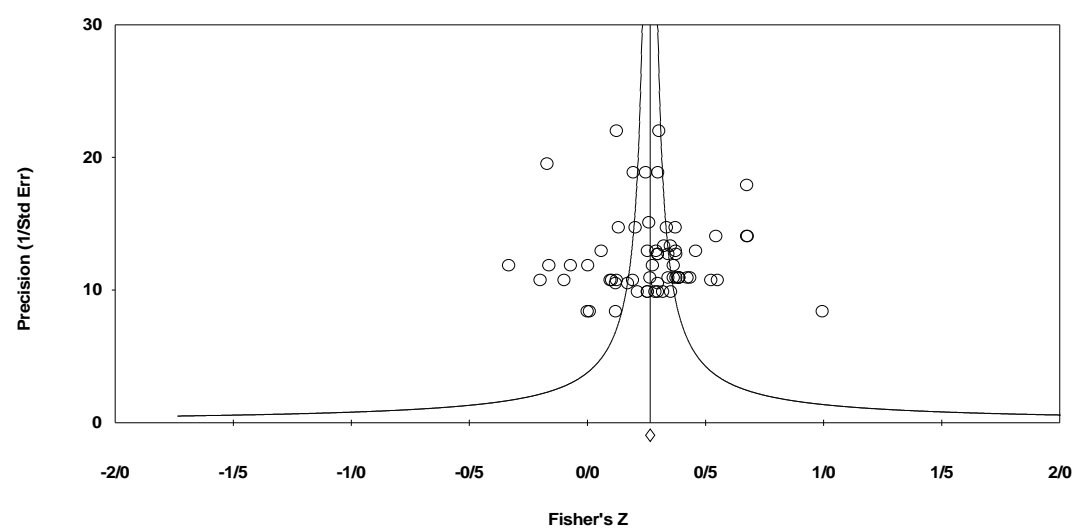

نمودار (Y): نمودار قيفى بر اساس شاخص دقت

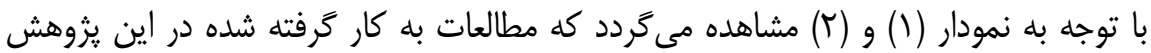
حول محور ميانگين اندازه اثر به طور متقارن توزيع نشده اند و يراكندگى مطالعات حول يكى طرف

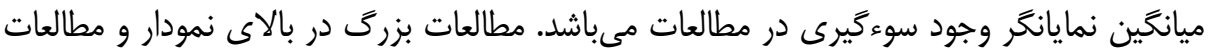

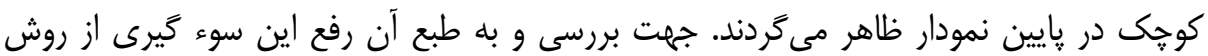

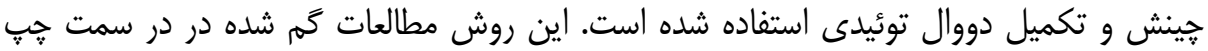

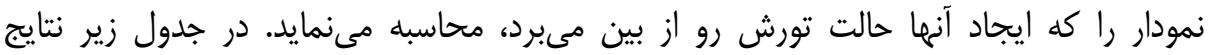
بكار گيرى اين روش گَزارش شده است.

جدول (ץ): روش جينث و تكميل دووال و توئيدى

\begin{tabular}{|c|c|c|c|c|c|c|c|c|}
\hline \multirow[t]{2}{*}{ Q ارزش Q } & \multicolumn{3}{|c|}{ اثرات تصادفى } & \multicolumn{3}{|c|}{ اثرات ثابت } & \multirow{2}{*}{ مطالعات } & \\
\hline & حد بالا & حديايين & تخطه & حد بالا & حديايين & تقطه & & \\
\hline 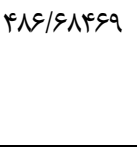 & r. & $\cdot / r \cdot q \cdot r$ & ./TE.V. & ./TVVA. & . Tfis. & . /TDQGY & & شارش \\
\hline ATI/DQDFT & - /TATMV & ./IrVgA &.$/ 19099$ & ./rIrqq & . / VVA A &.$/ 19998$ & ir & تعديل شده \\
\hline
\end{tabular}




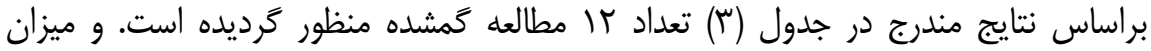

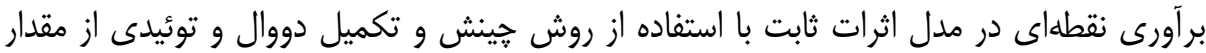

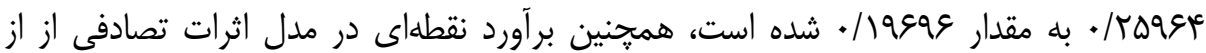

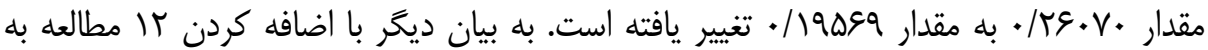

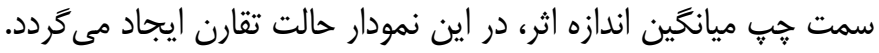

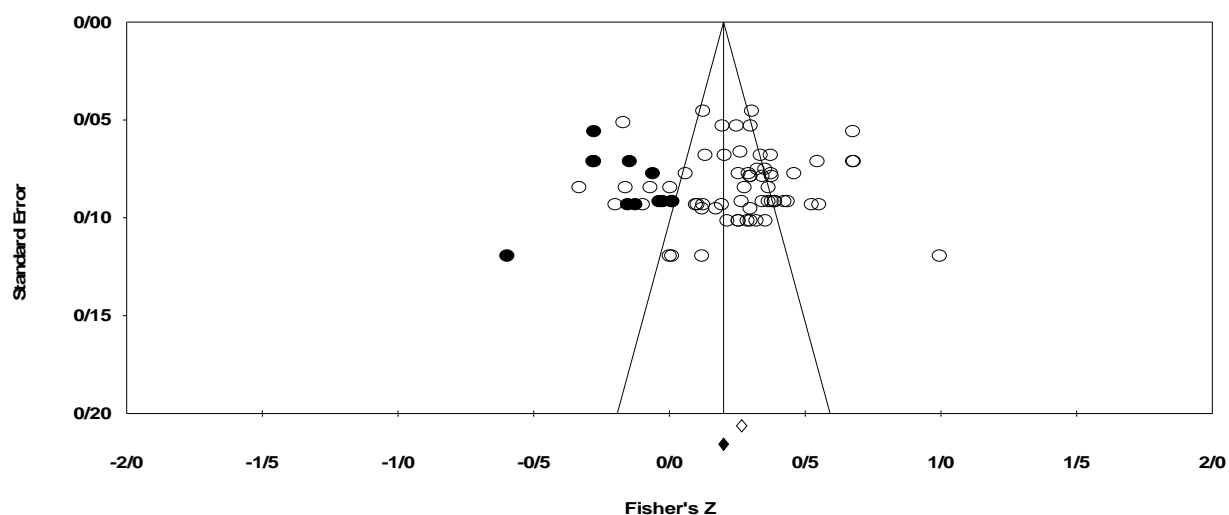

نمودار (س): نمودار قيفى اصلاح شده بر اساس شاخص خطاى استاندارد

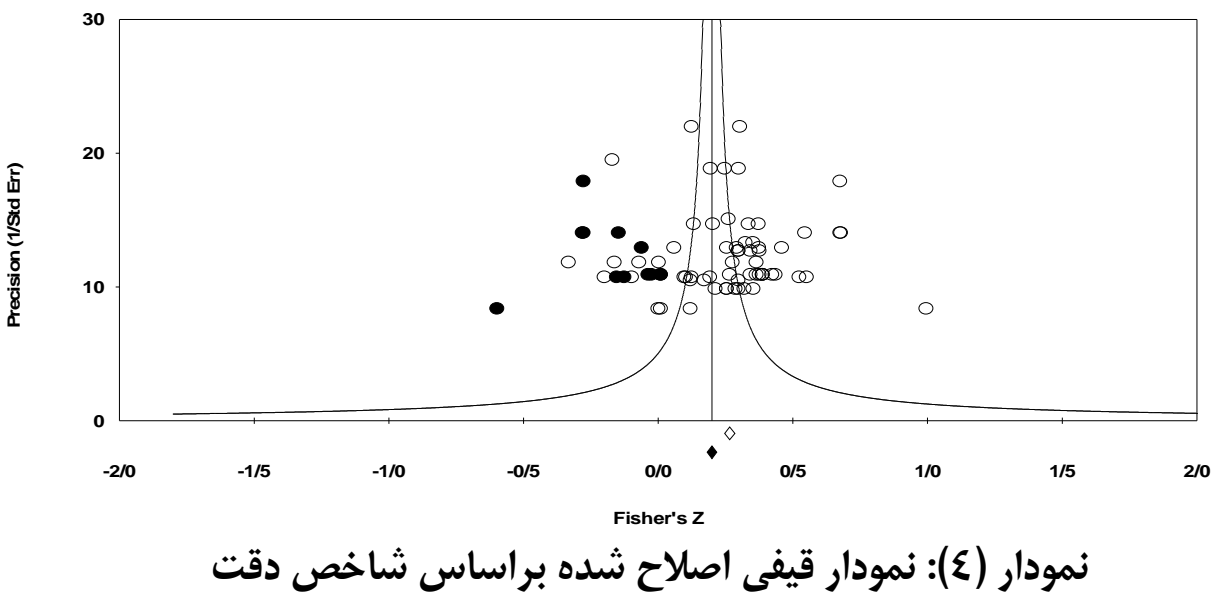




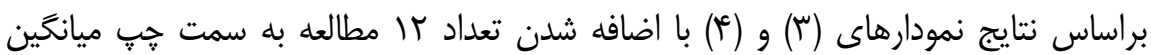

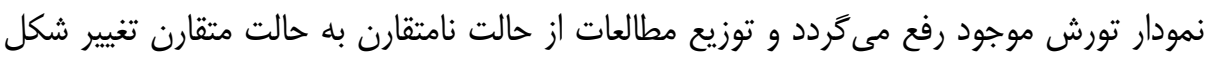

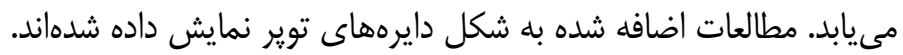

\section{بر سى همخَى مطالعات}

جهت بررسى ميزان همكنى مطالعات از آزمون Q استفاده شده است. نتايج مربوط به اين آزمون

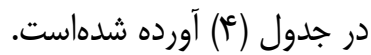

\begin{tabular}{|c|c|c|c|c|}
\hline$\frac{1}{I^{2}}$ & مقدار هي & $\mathrm{df}$ & Q مقدار & مدل \\
\hline . ITYYq. &.$/ \ldots$ & 91 & 19. & ثابت \\
\hline
\end{tabular}

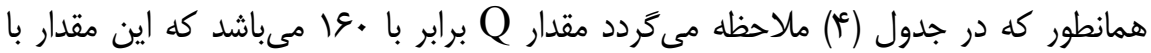

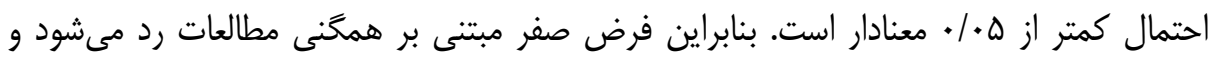

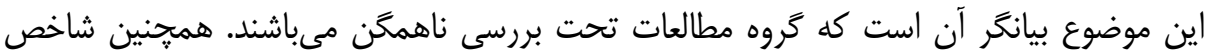

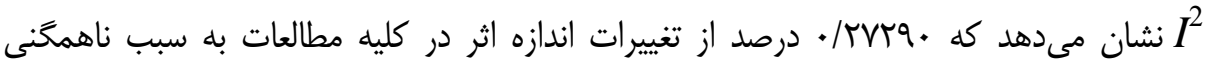

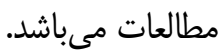

\section{محاسبه مقادير اندازه اثر هريك از مطالعات}

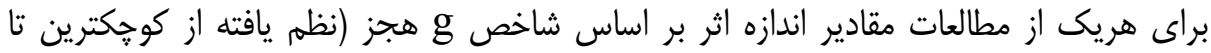

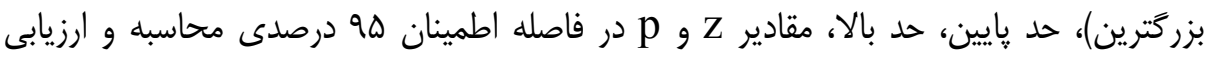

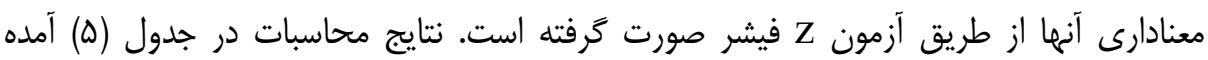

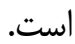


جدول (0): محاسبه اندازه اثر وآزمون معنادارى آن براى هر يك از مطالعات

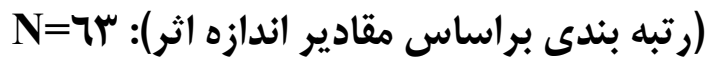

\begin{tabular}{|c|c|c|c|c|c|c|c|}
\hline \multicolumn{5}{|c|}{ شاخصهاى آمارى } & \multirow[t]{2}{*}{ متغيرها } & \multirow[t]{2}{*}{ نام يخوهشگر } & \multirow{2}{*}{$\cdot \frac{\hat{3}}{3}$} \\
\hline مقدار p p & مقدار Z & حد بالا & حد يايين & و هجز g & & & \\
\hline.$/ \ldots$ & -r/qMF &.$- / 194$ &.$- / 48$. & - & تاريخهِ & هويدا & 1 \\
\hline سז./. & -r/lrq & -.1 .18 & $-\cdot / \mu \& \Lambda$ &.$- / 198$ & تظاهر برتوليد & شايان جهرمى & r \\
\hline $.1 \cdot .1$ & - & -.1 .99 &.$- /$ TEF &.$- / 191$ & فرسودگى شغلى & ش شورونى & r \\
\hline$\cdot / \cdot \Delta S$ & $-1 / 91$ & $\cdot 1 \cdot+r$ & $-\cdot / \mu \backslash \varepsilon$ & $-\bullet / 19$ & همكاران & هويدا & f \\
\hline ./TqV & سع & $\cdot / \cdot \wedge \Delta$ &.$- / r V \mu$ & $-.1 .9 V$ & اعتماد & شايان جهرمى & $\Delta$ \\
\hline$\cdot / 4 \cdot V$ & $-\cdot / \wedge \mu$. & .1 .90 & ונות/.- & $-\cdot / \cdot V \cdot$ & سياست & هويدا & 8 \\
\hline ./994 & $\cdot 1+\cdot 1$ & | &.$- / 4 r q$ & $.1 \cdot+1$ & اختلال جسمانى & ابراهيمى & $v$ \\
\hline.$/ 9 V T$ & D מש./. &.$/ 19 V$ & $-\cdot|/| 9 \mid$ & r... & زبان & هويدا & $\wedge$ \\
\hline س س /9/. & $\cdot / \cdot \lambda r^{c}$ & $\cdot / T F$ & $-.4 T I$ & $.1 \cdot 1$ & اختلال خواب & ابراهيمى & 9 \\
\hline . & $\cdot / \mathrm{VV}$ & $\cdot / 4 \cdot 9$ & -.1 .91 & .1 .9 & تجربه گرايى & شريفى & 1. \\
\hline.$/ 498$ & $1 / 4$ &.$/ T V \mu$ &.$- \cdot 1 \cdot \wedge \Delta$ & $.1 .9 \mathrm{~V}$ & مانع & شايان جهرمى & 11 \\
\hline.$/ K \& \Lambda$ & $1 / 1 \cdot 1$ &.$/ 4 V q$ & $-.1 \cdot 19$ & $\cdot 11 \cdot r$ & كناره جويى & شايان جهرمى & ir \\
\hline$\cdot / T \cdot 9$ & I/TED & ./rq4 & -.1 .99 &.$/ 1 r$. & عدالت رويه ايى & قالاوندى & سו \\
\hline (TוK & $1 / \cdot .9$ & . &.$- / 11 \pi$ &.$/ 1 r$. & اختلال كاركردى & ابراهيمى & 14 \\
\hline $.1 . .9$ & $r / r m q$ &.$/ 411$ & ./.ra &.$/ M T E$ & عدالت توزيعى & عبداللهى & 10 \\
\hline$\cdot|\backslash \wedge|$ & I/rm &.$/ 491$ & $-\cdot / \cdot \Delta \Lambda$ & . ITE & تاكيد بر توليد & شايان جهرمى & 19 \\
\hline $.1 \cdot 01$ & $1 / 901$ & . & $-. / \cdot+1$ & - & شباهت & محمدى & IV \\
\hline$\cdot 1 \cdot \mathrm{Vr}$ & $\cdot / \Lambda \cdot 1$ & . /MFi &.$- \cdot 1 \cdot 10$ &.$/ 1 \mathrm{~V}$ & عدالت تعاملى & قلاوندى & 11 \\
\hline.$/ \cdot \mu$ & $r / \cdot V r^{c}$ & . $/$ TQq & .1 .11 &.$/ 191$ & ملاحضه كرى & شايان جهرمى & 19 \\
\hline $.1 \ldots$ & r/द八 &.$/ 491$ & 1.91 &.$/ 194$ & عدالت رويه ايى & 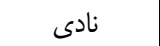 & $r$. \\
\hline..$+ \mu$ & $r / 99 \Delta$ & . & $\cdot 1 \cdot \mathrm{v}$ & $\cdot / r \cdot 1$ & نفس كار & محمدى & r \\
\hline ع ع ./. & $r / .99$ &.$/ 4 q$. & .1 .14 & $\cdot|r| \cdot$ & معنادارى & طهماسب زاده & rt \\
\hline.$/ \cdots$ & $r / 9 V T$ & אוז/. & س & ת & عدالت تعاملى & 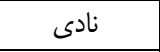 & זr \\
\hline $.1 \cdot 14$ & $r / \Delta 18$ & . אTE & $.1 . \Delta 9$ & $\cdot / K \Delta$. & קشم اندازه سازمان & طهماسب زاده & re \\
\hline $.1 \cdot 14$ & $T / D \mid G$ & . & $\cdot / \cdot \Delta g$ & $\cdot / T \Delta$. & عضويت & طهماسب زاده & $r \Delta$ \\
\hline $.1 \cdot 1$ & $r / \mu+1$ & •/ MN & $\cdot / 1 \cdot r$ &.$/ T \Delta$. & روانجورخويى & شريفى & re \\
\hline.$/ \ldots$ & r/q4D & ( & (III) & . /TAF & احساس شايستخى & عابدى & TV \\
\hline$\cdot / \cdot r$ & $r / q . r$ &.$/ 411$ & $.1 \cdot 18$ & . Kq. & فناورى & قدرى & rᄉ \\
\hline $.1 .+1$ & r/TVE &.$/ 419$ &.$/ 111$ &.$/ 4 V$. & اهداف و ارزش ها & هويدا & rq \\
\hline
\end{tabular}


هديريت بر آهوزش سازمانها

\begin{tabular}{|c|c|c|c|c|c|c|c|}
\hline$\% \omega$ & 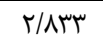 &.$/ F A T$ & $\cdot / \cdot M$ &.$/ T \Lambda$. & بازخورد عملكرد & طهماسب زاده & r. \\
\hline$\%$ & $r / W T^{c}$ &.$/ 4 I V$ & ./1rq & . /TAF & وظيفه شناسى & شريفى & ו ו \\
\hline.$/ . r$ & 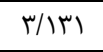 &.$/ F Q 1$ &.$/ 111$ &.$/ 49$. & عدالت توزيعى & قاوندى & r \\
\hline.$\cdots$ & $r / v M$ & . LFt & ת &.$/ 49$. & استشهاد فعال & رضان نزاد & או \\
\hline $.1 \ldots$ & $r / v M$ & . LTE & سזאו &.$/ 49$. & استشهاد غير فعال & رضان نزاد & me \\
\hline.$/ . r$ & r/qFi & .149 & .1 .99 &.$/ r q$. & تعهد در سازمان & طهماسب زاده & w \\
\hline 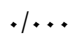 & D/A广द & אוץ/. & ./194 &.$/ 491$ & سرمايه اجتماعى & نادى & عس \\
\hline 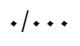 & G/GAT &.$/ v^{2}$ &.$/ 4 I T$ &.$/ 490$ & عدالت تعاملى & عبدالهى & rv \\
\hline.$/ \cdot r$ & $r / I \Delta V$ &.$/ 4 \mathrm{Fr}$ &.$/|r|$ &.$|\mu| \cdot$ & ايمان & طקماسب زاده & rᄉ \\
\hline.$\cdots$ & F/rTf & . k4t. &.$/ 1 V 9$ &.$/ \mu I f$ & وظيفه مدار & علمى & rq \\
\hline$\%$ & $4 / 94$. & אואוא. & $\cdot / 4+$. & ./MTF & وفادارى & محمدى & i. \\
\hline$\%$ & $\Gamma / \Gamma \Delta$. & .149. &.$/ 1 \wedge \varepsilon$ & . & سبك عملغر ايى & رمضان نزاد & i) \\
\hline.$\cdots$ & $r / V F^{2}$ &.$/ 4 \lambda$. &.$/ 194$ & • & شخصيتى & قدىى & et \\
\hline$\%$ & r/sqs &. IFA & $\cdot / 4 \cdot r$ & وسm/. & رابطه مدار & علمى & w \\
\hline $.1 \ldots$ & r/זAV & $\cdot / \Delta \cdot r$ & - /TAF &.$/ M r$. & نوع دوستى & طهماسب زاده & pe \\
\hline$\%$ & $\mathrm{r} / \mathrm{quV}$ &.$/ 498$ &.$/ M A F$ &.$/ \mu \omega$ & رفتارى & قدىى & $i \Delta$ \\
\hline $.1 \cdots$ & F/MTY &.$/ 4 \wedge S$ &.$/ 198$ &.$/ N \Delta$ & وظيفه & هويدا & is \\
\hline $.1 \ldots$ & $\Delta / \leftarrow M$ &.$/ 49 V$ & תמא/. &.$/ T \Delta V$ & دلبستخى & محمدى & iv \\
\hline $.1 \cdots$ & $F / \lambda F \mid$ & . א^ル &.$/ 719$ & $\cdot / \mathrm{r} \Delta \Lambda$ & همسازى & شريفى & $i \wedge$ \\
\hline $.1 \cdots$ & $5 / 111$ & $\cdot 10 \cdot 0$ &.$/ 190$ & . & آموزشى & قدرى & 19 \\
\hline$\%$ & r/VAr &.$/ 4 \wedge S$ &.$/ 419$ & . & ياداش مشروط & رمضان نزاد & $\omega$. \\
\hline 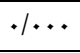 & $f / T r V$ &.$/ 014$ &.$/ 4 \cdot 9$ &.$/ \mathrm{V} V$ & اخلاق حرفه اى & قدرى & 01 \\
\hline$\%$ & F/TMV &.$/ Q 1 f$ & $\cdot / 4 \cdot 9$ & $\cdot / \mathrm{rV} \cdot$ & فكرى & قدرى & $\Delta T$ \\
\hline $.1 \cdots$ & F/TMV &.$\left.|\Delta|\right|^{f}$ &.$/ 4 \cdot 9$ &.$/ T r$ & توسعه حرفه اى & قدرى & $\Delta r$ \\
\hline $.1 \cdots$ & F/gTI &.$/ \Delta T_{q}$ & . & $\cdot / 4 \cdots$ & تدريس & قدىى & $\Delta f$ \\
\hline.$/ \cdots$ & r/VQT & $\cdot / \Delta \uparrow \wedge$ & $\cdot / r \Delta$ &.$|4|$ & صلاحيت حرفه اي & قدرى & $\Delta \omega$ \\
\hline $.1 \cdots$ & D/QF &.$/ \Delta F \Delta$ &.$/ 799$ & . & برون گرايى & شريفى & $\Delta \varphi$ \\
\hline$\%$ & D/ATY & .19 .9 & ./rrq & $\cdot \mid \& \wedge 1$ & نشاط & شايان جهرمى & $\Delta V$ \\
\hline $.1 \ldots$ & $V / G \Delta F$ & .1090 & $\cdot /$ rAD &.$/ 498$ & نكرش & مرادى & $\Delta \wedge$ \\
\hline.$/ \ldots$ & $0 / 919$ & . & . & $\cdot 10 \cdot r$ & صميمت & شايان جهرمى & 09 \\
\hline $.1 \ldots$ & $q /<q$. &.$/ 9 V r$ &.$/ 4 q$. & .1019 & دانش & مرادى & 9. \\
\hline $.1 \cdots$ & $15 / .90$ & $.19 \Delta 9$ & . & .1019 & سرمايه اجتماعى & راد & 91 \\
\hline $.1 \cdots$ & ( &.$/ 8 V^{e}$ &.$/ 494$ & .1091 & مهارت & مرادى & gr \\
\hline.$\cdots$ & N/RTD & سז/A & . latt & ./VG. & اختلال افسردگى & ابراهيمى & سو \\
\hline
\end{tabular}


در جدول (ع) ستون اول نشاندهنده نام محقق مىباشد، در ستون دوم زير متغيرها براى

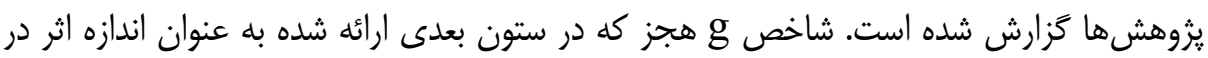

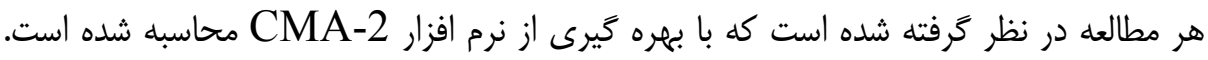

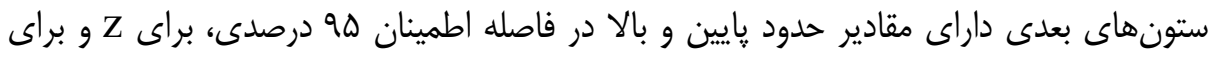

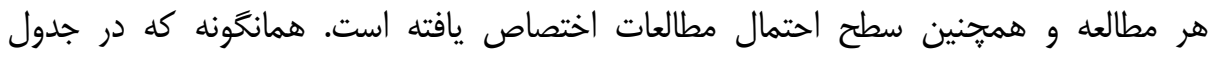
مشاهده مى گردد، به استثناى مطالعات هويدا (سياست و زبان)، جهرمى (اعتماد، مانع، كناره جويى،

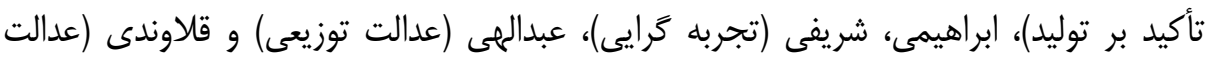

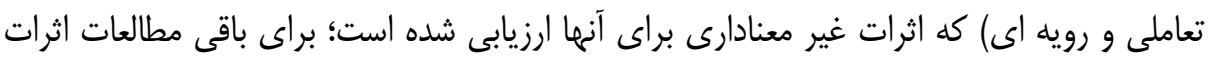
معنادار ززارش شده است.

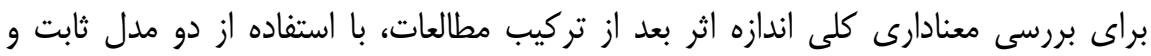

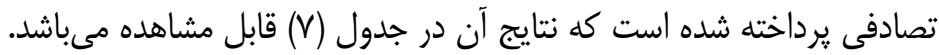

\section{جدول (V): نتايج تركيب اندازه اثر مطالعات و معنى دارى آنها}

\begin{tabular}{|c|c|c|c|c|c|c|c|}
\hline \multicolumn{2}{|c|}{ محاسبه ميانخين اثرات } & \multicolumn{5}{|c|}{ شاخصهاى آمارى } & \multirow[t]{2}{*}{ 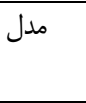 } \\
\hline منفى & مثبت & مقدار p p & Z مقدار Z & حد بالا & حد پايين & g وجز & \\
\hline \multirow[t]{2}{*}{.$/ 19 \Lambda$} & \multirow[t]{2}{*}{./TAV } &.$/ \cdots$ & $r \cdot \Lambda r q$ & $. / T / f$ & $.1+19$ &.$/ 1 \Delta \Lambda$ & ثابت \\
\hline & &.$/ \cdots$ & - DFTV &.$/ T V A$ & . MET & . & تصادفى \\
\hline
\end{tabular}

همانطور كه در جدول (V) مشاهده مىشود مقدار اندازه اثر كلى براى مطالعات در مدل اثرات

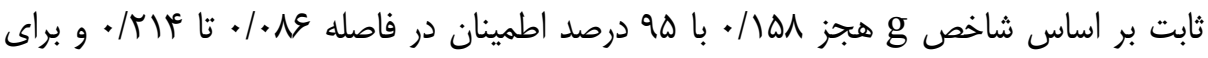

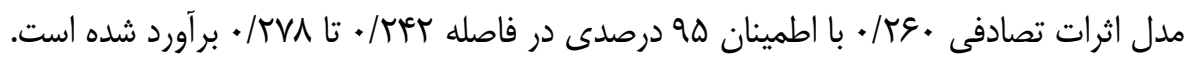

\section{بررسى سو تَيرى انتشار مطالعات}

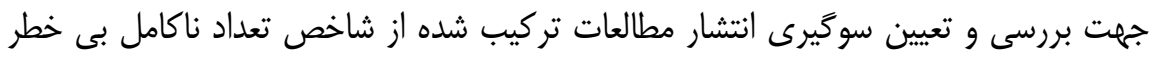

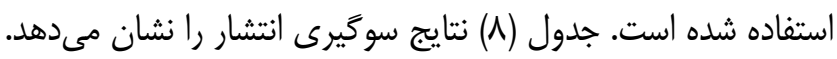




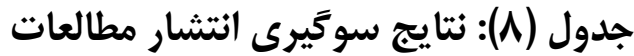

\begin{tabular}{|c|c|c|c|c|c|}
\hline تعداد مطالعات & تعداد مطالعات & Z آلفا Z & مقدار آلفا & مقدار P & مشاهده شده مطالعات \\
\hline | וצץ| & سو & $1 / 90998$ & $\cdot / \cdot \Delta+\cdots$ &.$/$ & re/rq।qr \\
\hline
\end{tabular}

نتايج جدول (^) نشان مىدهد كه تعداد اوسا مطالعه كَمشده با اندازه اثر برابر با صفر نياز

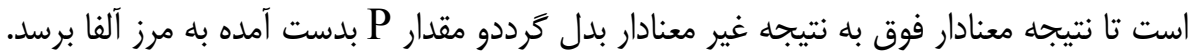

\section{تركيب احتمالات مطالعات در يزوهش}

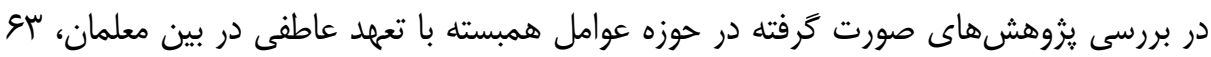

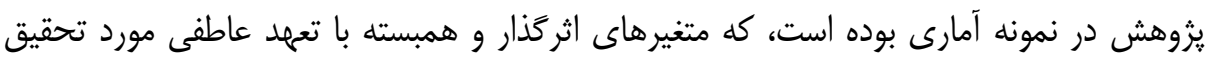

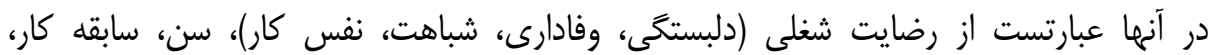

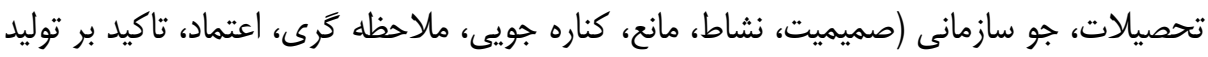

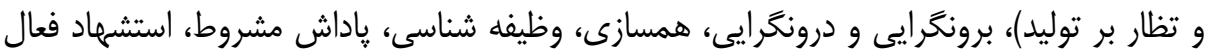

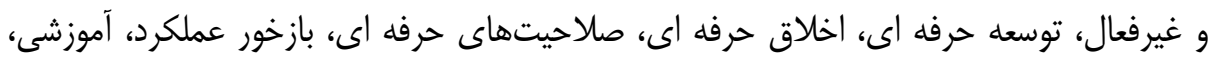

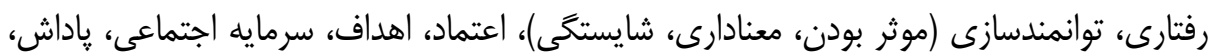

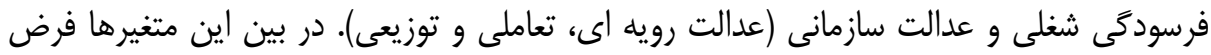

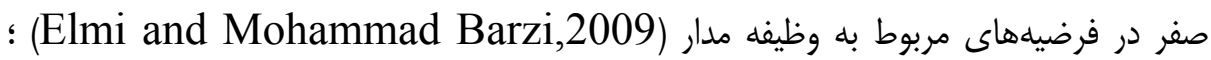

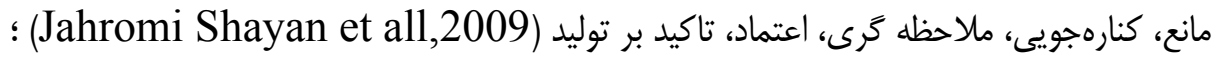

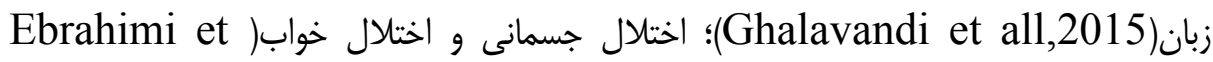

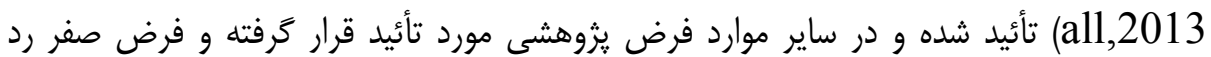

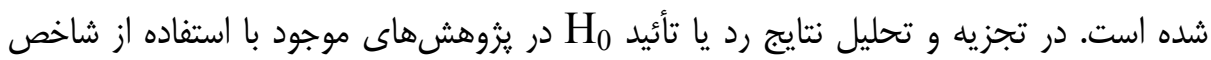

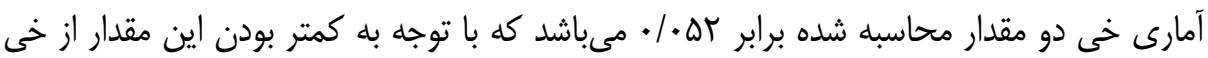
دو بحرانى، مقدار محاسبه شده در سطح هـ / معنار ماسهار مى مباشد. 


\section{بحث و نتيجه كيرى}

يكى از مسئوليتهاى هر نهاد اجتماعى، نيل به اهدافى است كه علت وجئ وجودى آن نهاد نهاد را شكل

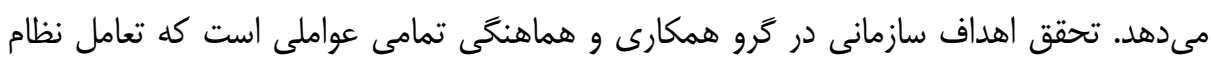

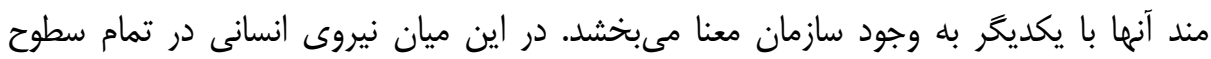

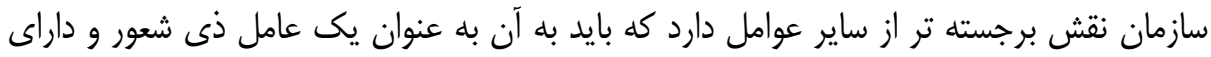

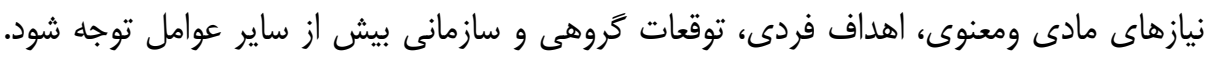

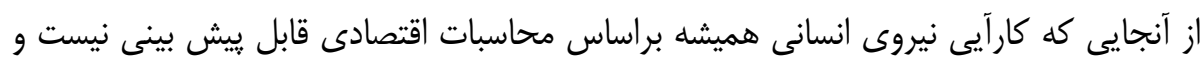

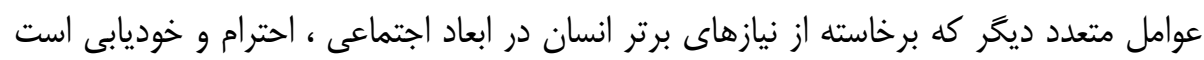

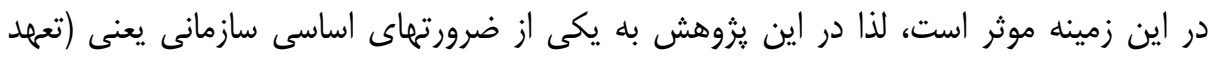

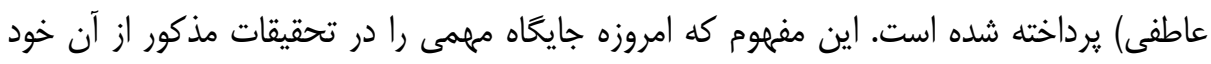

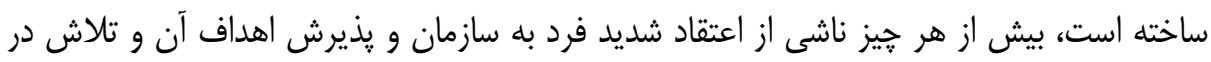

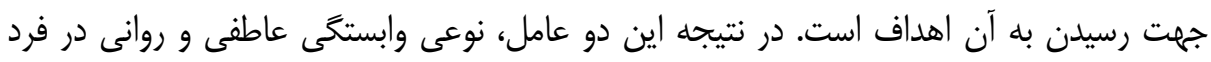

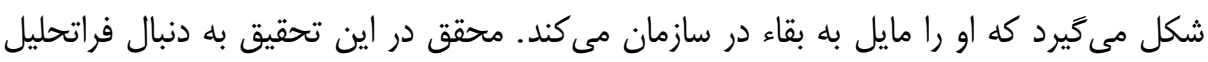

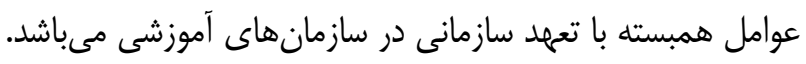

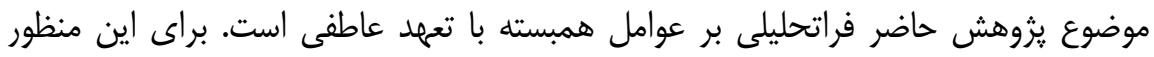

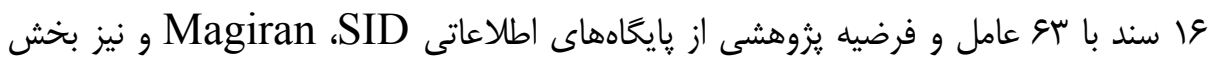

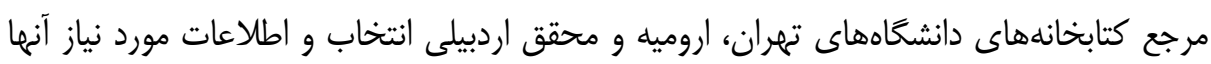

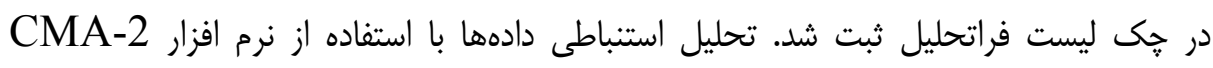

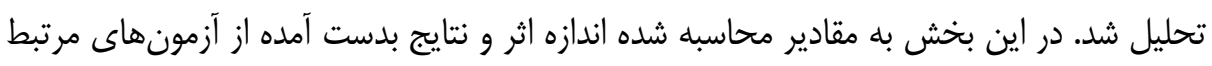

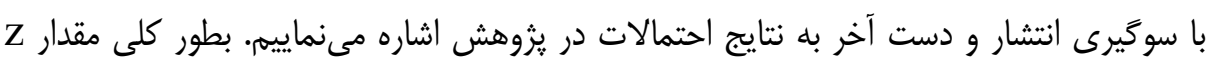

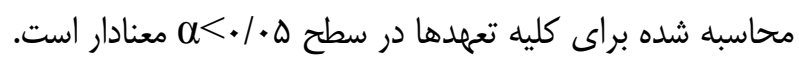

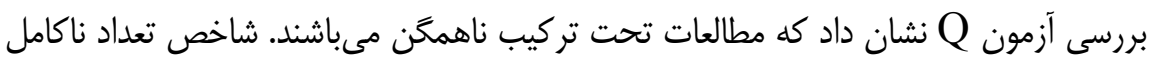

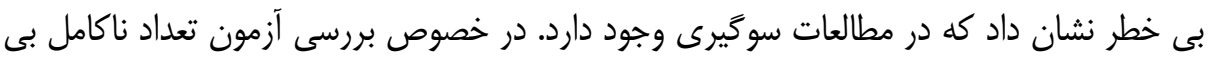

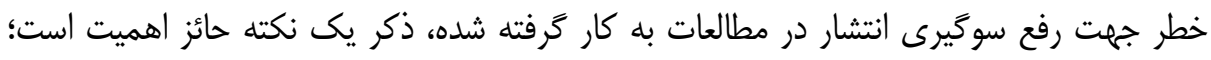

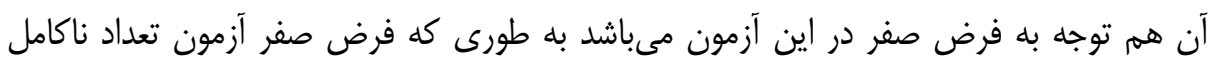

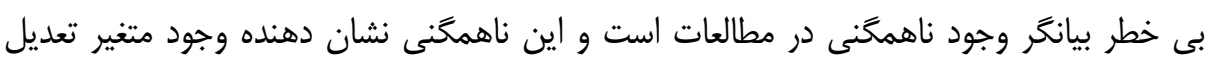

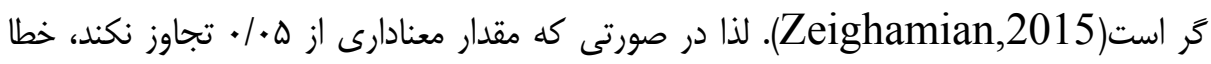


رخ مىدهد و اين خطا كه در طول تحقيق مشهود است به سبب نامحتمل بودن افزودن تعداد

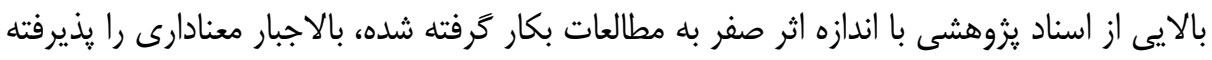

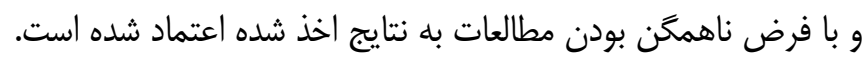

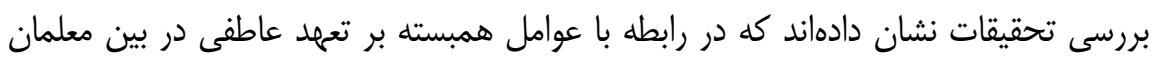

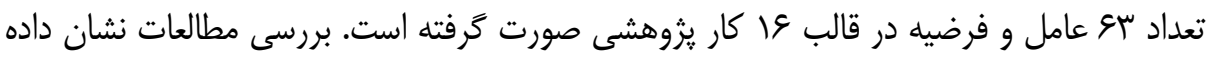

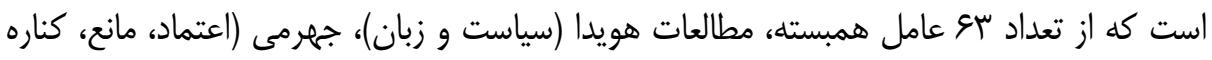

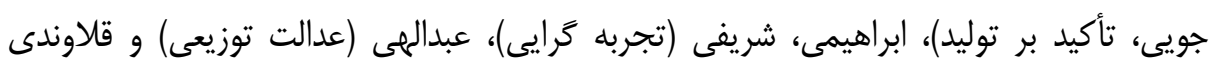

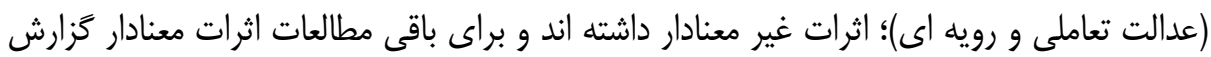

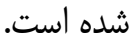

بطور كلى از نتايج فراتحليل مطالعات حوزه تعهد عاطفى نشان داد كه متغيرهاى اثركذار و و

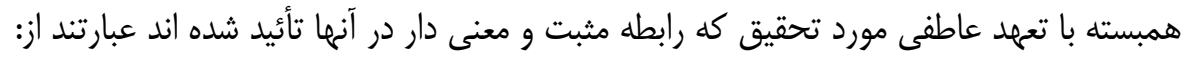

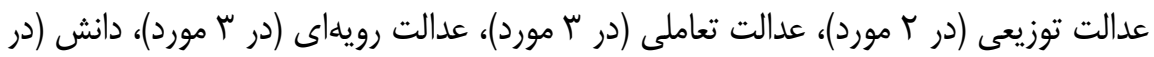

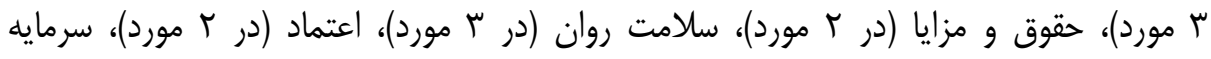

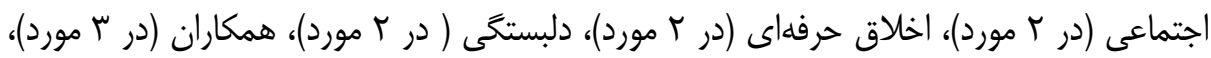

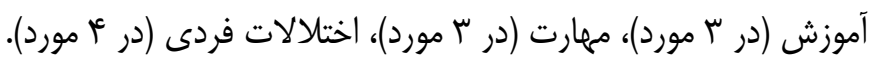

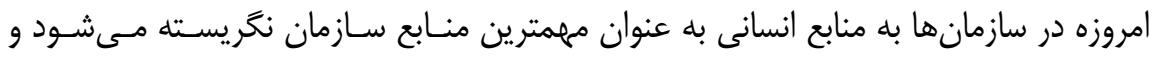

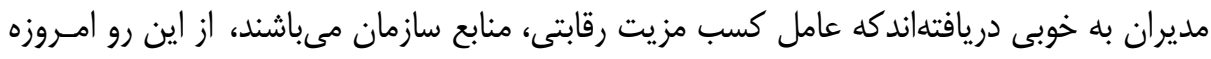

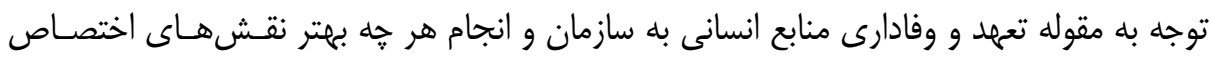

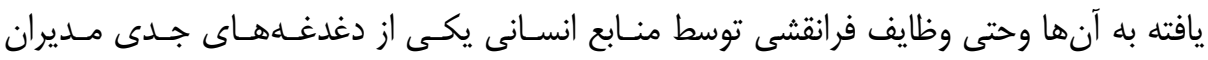

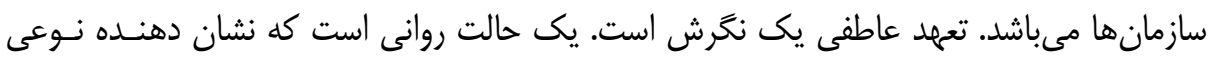

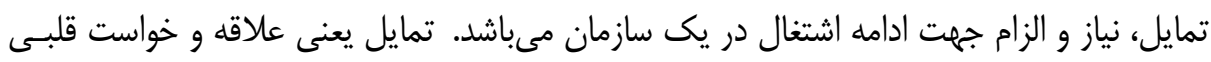

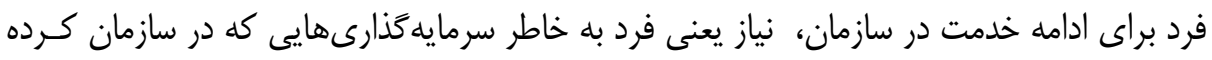

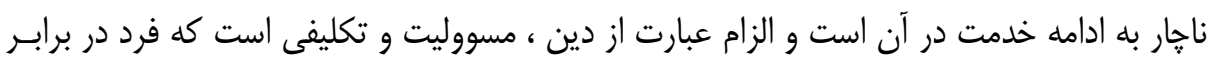

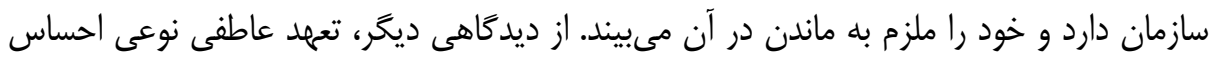

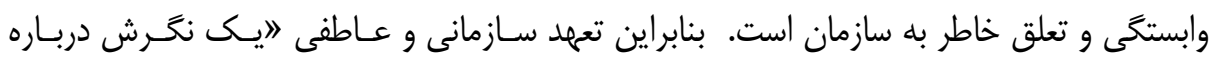

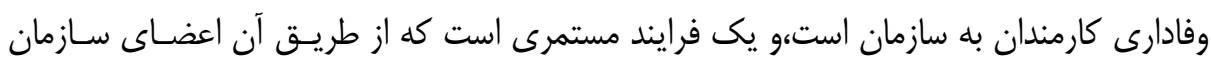
علاقه خود را به سازمان و موفقيت و كارايى ييوسته آن نشان مى دهند (Majidi,1998). 
در بحث از نتايج تحقيق حاضر و تطبيق آن با نظريههاى مطرح شده در كذشته، نزديكترين و

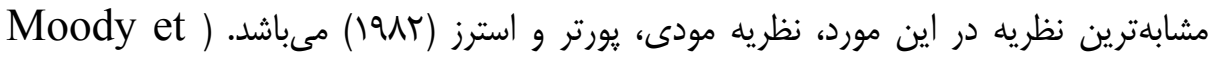

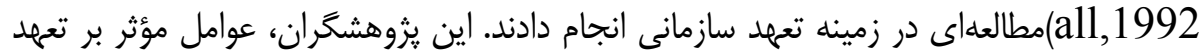

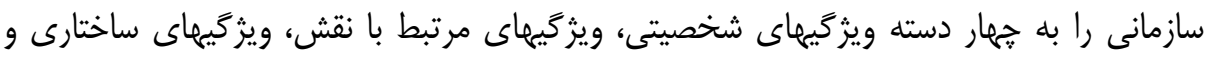

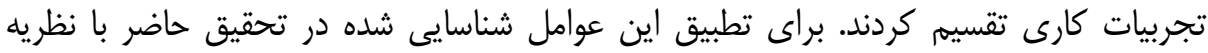

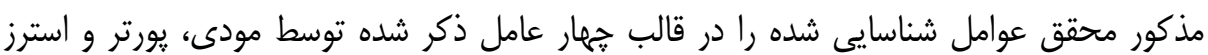
(1914) (1914) ذكر مكى كند.

همانطور كه در قسمت نتايج تحقيق مشخص شده در دمر زمينه عوامل شخصيتى همبسته با تعهد

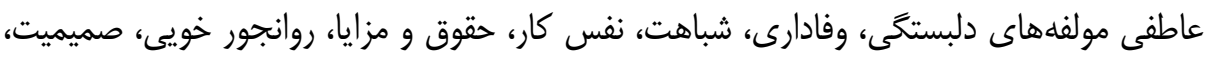

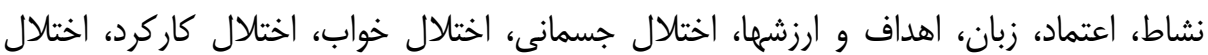

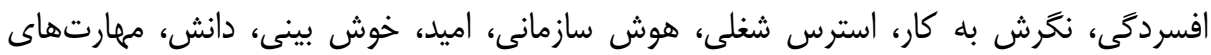

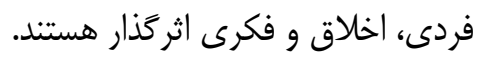

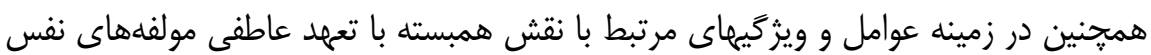

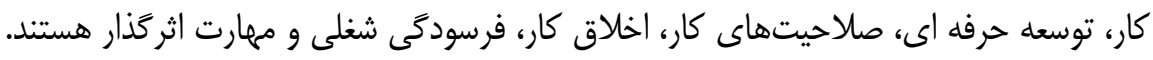

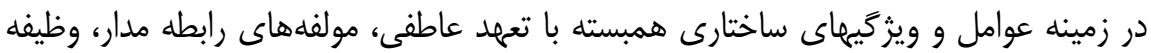

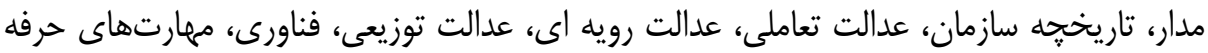

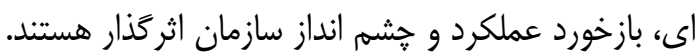

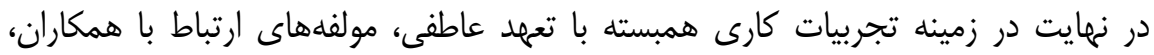

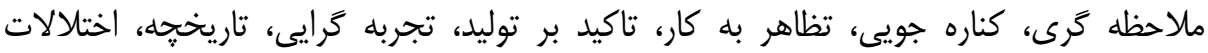

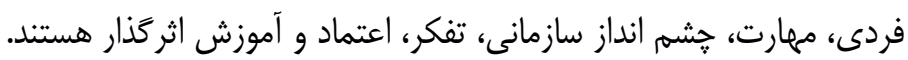

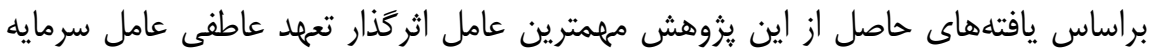

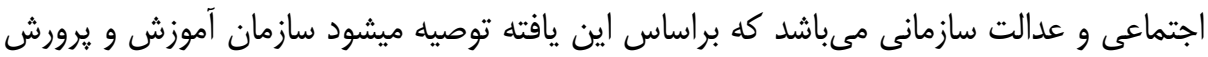

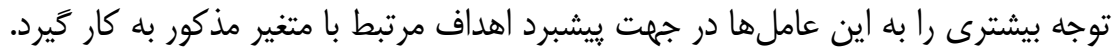

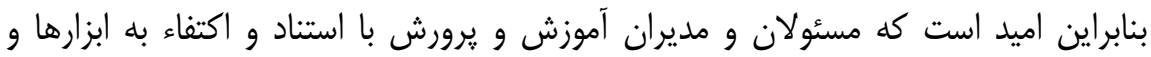

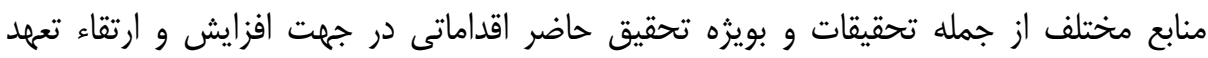
عاطفى معلمان مبذول بدارند. 
با توجه به فراتحليل صورت كَرفته، مشخص كَرديد كه توجه بيشتر يُوهشكَران به مسائل

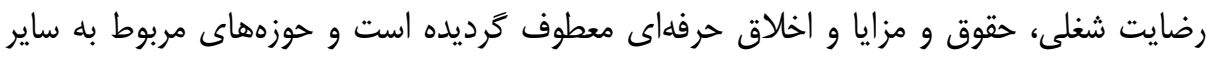

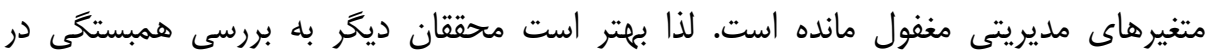
حوزههاى ديكر مديريت با تعهد سازمانى بيردازند.

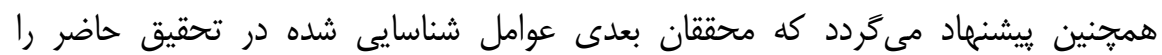

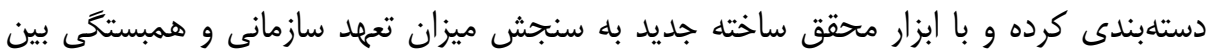
متغيرهاى سازمانى و عهد سازمانى بيردازند.

\section{محدوديت ها}

يكى از اصلى ترين محدوديتهاى اين تحقيق كه بروهشكَر راد در بسيارى از موارد با شك و و ترديد

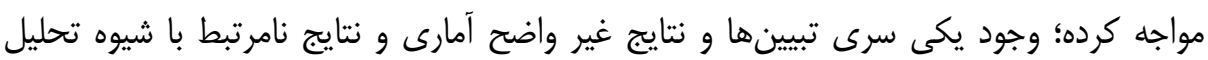

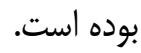

محدوديت ديكر تحقيق عدم كزارش شاخصها و آمارههاى مورد نياز براى برآورد اندازه اثر در

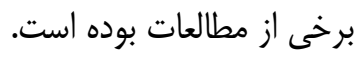

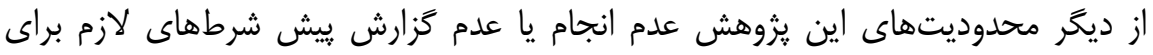

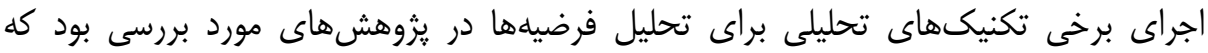

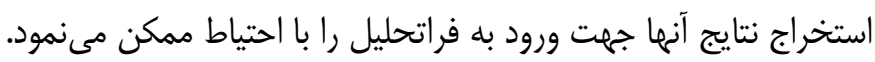

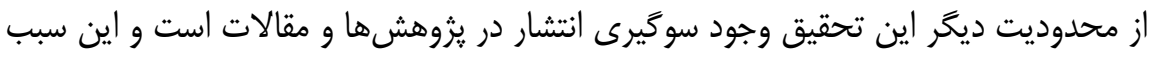
مىشود تا تعميم يافتهها با احتياط انجام كَيرد.

\section{تعارض منافع /مالى حمايت}

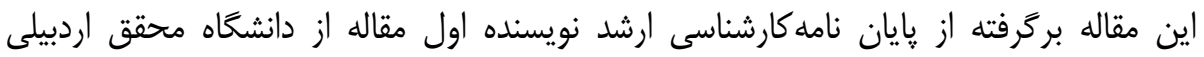

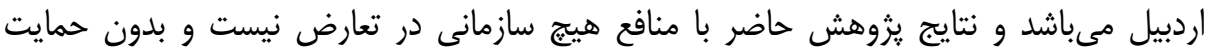

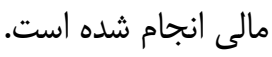
منابع

1. Abdollahi, B., Yousefiani, Gh. A. \& Hatamian, J. (2012). The Relationship between Components of Organizational Justice and Organizational Commitment in Elementary School Teachers, New 
Educational Thoughts, Faculty of Educational Sciences, Al-Zahra University, Vol 10, No 2, pp. 118-92. [in Persian]

2. Abedi, R., Razavi, M. H., Farzan, F \& Khadem,A. (2015). Investigating the relationship between competency and components of teachers' organizational commitment and physical education. Journal of Sports Management and Motor Behavior, Vol 11, No 22, pp. 45-30. [in Persian]

3. Ardalan, M,.Tajbi, M \& Majouni,H. (2019). The role of ethical leadership in organizational citizenship behaviors mediated by organizational justice and organizational commitment. Management on training organizations. Eighth Year, No. 2, pp. 11-46. [in Persian]

4. Bahmani, A., Mahdavi Rad, M. R., \& Balouchi, H. (2016). The Effect of Organizational Cynicism on theQuality of the Offered Services with Organizational Commitment Moderated. Management Researches, 9(31), 161-185. )in Persian).

5. Chevroni, Safara (2014). Investigating the relationship between job burnout and organizational commitment among primary school teachers in district 2 of Karaj, Master's thesis, Faculty of Educational Sciences and Psychology, University of Tehran. [in Persian]

6. Ebrahimi, A,.Zainali,Sh,. Dodman, M. K., \& Hassanloui, F (2013). Investigating the Relationship between Mental Health Components and Dimensions of Organizational Commitment (Case Study: Piranshahr Public School Teachers), The Second National Conference on Modern Management Sciences in Golestan Province. [in Persian]

7. Elmi, M \& Mohammad Barzi, A. (2009). Investigating the Relationship between Managers' Management Style and Organizational Commitment of Buchanan Secondary Education Teachers, Sociology 1, No. 3, pp. 5027. . [in Persian]

8. Ghalavandi,H., Alizadeh,S \& Alizadeh,M. (2015). The Relationship between Perceived Organizational Justice and Organizational Commitment: A Case Study of Female Teachers in Naghadeh, Journal of School Psychology, Vol 4, NO 4,PP 11-124.[in Persian]

9. Ghanizadeh Graili, M,.Jafari, P \& Ghorchian, N. G. (2017). The effect of professional competencies on the improvement of high school teachers in Tehran province. Management on training organizations. Sixth Year, No. 1, pp. 51-72.

10. Hoveida, R,. Jamshidian, A \& Mokhtarifar, H .(2011). The Relationship between Organizational Socialization and Organizational Commitment among Secondary School Teachers in Hamadan, Applied Sociology, Volume 22, Number 3, pp. 82-63. [in Persian] 
11. Jahromi Shayan,A,. Shapoor, A., Ahmadi, E \& Darvishpour Faragheh, S. (2009). Investigating the Relationship between Organizational Climate and Organizational Commitment and Morale from the Perspective of Middle School Teachers in Marvdasht in the Academic Year of 20082009, A New Approach in Educational Management, Vol 2, No 3, pp. 130-109. [in Persian]

12. Kazemi,F \& Zare,A.(2019). The Relationship between Offensive Supervision of Organizational Citizenship Behavior and Organizational Emotional Commitment: Explaining the Mediating Role of Employees' Perception of Interactive Justice. A New Approach in Educational Management, Vol 10, No 4, pp. 233-210. [in Persian]

13. Majidi, A. (1998). Investigating the Impact of Job Transfer on Job Satisfaction and Organizational Commitment of Employees, M.Sc. Thesis, Tehran, Tarbiat Modares University. [in Persian]

14. Mohammadi, S. (2007). Investigating the Relationship between Organizational Identity, Job Satisfaction and Organizational Commitment among High School Teachers in Sanandaj, M.Sc. Thesis, Faculty of Educational Sciences and Psychology, University of Tehran. [in Persian]

15. Moody, R.T., Steers, R.M. \& Porter, L.W. (1992). The Measurement of Organizational Commitment, Journal of Vocational Behavior, 14, pp. 224-247.

16. Moradi, S \& Talepasand, S .(2015). Multiple Relationships of In-Service Training, Empowerment and Organizational Commitment, Management and Planning in the Educational System, Vol 9, No 16, pp. 68-49. [in Persian]

17. Motahari Nejad, H \& Gemini, H. (2020). Analysis of structural relationships of professional learning community and teachers' commitment with the mediating role of collective efficiency. Management on training organizations. Ninth Year, No. 1, pp. 91-113. [in Persian]

18. Nadi, M., Rumi, H \& Toghraei, B. (2012). The Relationship between Social Capital and Organizational Justice with Organizational Commitment Based on the Structural Equation Model among Female Teachers in Isfahan Girls' High Schools, New Educational Approaches, Faculty of Educational Sciences and Psychology, Isfahan University, Volume 7, Number 2, pp. 120-97. [in Persian]

19. Nazem, F \& Qaed Mohammadi, M. (2008). Organizational Commitment of Managers and Its Components in Islamic Azad University, Quarterly 
Journal of New Thoughts in Educational Sciences, Fourth Year, First Issue, pp. 11-28. [in Persian]

20. Qadri, I (2014). The Study of the Relationship between Professional Qualifications and Organizational Commitment of High School Teachers in Chabahar, Master's Degree, Faculty of Educational Sciences and Psychology, University of Tehran. [in Persian]

21. Rad, F \& Sharifi, A. (2014). Analysis of the role of social capital in the organizational commitment of teachers in Marand in the academic year 91-92, Sociological Research, Vol 8, No 1, pp. 124-111. [in Persian]

22. Ramezani Nejad, R. H.,mmatinejad, M. A., Andam, R., Zare, S \& Sadeghpour, N. (2011). Relationship between normative and pragmatic leadership styles of school principals with organizational commitment of physical education teachers, research in sports management and motor behavior (motor sciences and sports), Vol 1 (9), No. 1, pp. 72-63. [in Persian]

23. Sharifi, S., Salimi, Gh. A. \& Ahmadi, A. (2010). Investigating the Relationship between Personality Traits and Organizational Commitment in Principals and Teachers of Elementary, Middle and Secondary Schools in Khansar County, Quarterly Journal of New Approach in Educational Management, Voume 1, No4, pp. 106-81. [in Persian]

24. Shuroni, S. (2014). Investigating the Relationship between Burnout and Organizational Commitment among Primary School Teachers in District 2 of Karaj, M.Sc. Thesis, Faculty of Educational Sciences and Psychology, University of Tehran. [in Persian]

25. Tahmasebzadeh Sheikh Lar, D and Darwishi, B (2016). The Relationship between Spiritual Leadership Styles of Educational Managers with Organizational Commitment of Teachers, Educational Management Innovations, Vol. 11, No. 4 (44), pp. 36-22. [in Persian]

26. Zeighamian, S. (2015). Meta-Analysis of Factors Affecting Motivational Strategies, M.Sc. Thesis, Faculty of Educational Sciences and Psychology, Mohaghegh Ardabili University. [in Persian] 